\title{
ПОЛИТИЧЕСКИЕ КОММУНИКАЦИИ
}

\author{
Кшеменецкая М.Н.
}

\section{СОВРЕМЕННЫЕ МЕХАНИЗМЫ И ТЕХНОАОГИИ ПОАИТИЧЕСКОЙ КОММУНИКАЦИИ В ГОСУААРСТВЕННОМ УПРАВАЕНИИ РОССИИ}

\begin{abstract}
Аннотация. Предметом исследования являются современные механизмы и технологии политической коммуникачии как процесса и структуры информачионных обменов между ключевыми политическими акторами в государственном управлении России. В статье рассмотрены такие механизмы политической коммуникачии как: 1) механизм долгосрочной и доверительной коммуникации между органами государственной власти и обществом, 2) механизм политической коммуникачии на центральном, региональном и местном уровнях принятия государственных решений, 3) механизм электронной правительственной коммуникации, 4) механизм электронного политического участия в государственном управлении. В рамках выделенных механизмов рассмотрены электронные технологии политической коммуникации в государственном управлении, которые трансформируют природу коммуникации между государством, средствами массовой информации и обществом. Методология исследования основана на использовании как теоретических, так и прикладных разработок в области политической коммуникативистики и государственного управления, включает в себя модели электронной демократии и электронного правительства, а также анализ электронного участия. Новизна исследования заключается в рассмотрении современных моделей электронной демократии и ее технологий (электронных петиций и консультаций, вовлечения в проводимый политический курс, общественной дипломатии, повышения прозрачности работы государства, преодоления иифрового разрыва), механизма политической коммуникачии на чентральном, региональном и местном уровнях принятия государственных решений, моделей электронного правительства и особенностей электронного политического участия.
\end{abstract}




\section{ПОАИТИКА И ОБЩЕСТВО • 4 (136) • 2016}

Кнючевые слова: механизм, технология, политическал коммуникация, государственное управяение, уровни государственных решений, электронная демократия, электронное правительство, электронное участие, средства массовой информации, Россия.

Abstract. The subject of this research is the contemporarymechanisms and techniques of political communication as the process and structure of information exchange between the key political actors in the state administration of Russia. The article examines such mechanisms of political communication as: 1) mechanism oflong-term and trustworthy communication between the bodies of government authority and society; 2) mechanism of political communication on the central, regional, and local levels of making state decisions; 3) mechanism of electronic government communication; 4) mechanism of electronic political participation in state administration. Within the framework of the highlighted mechanisms, the author reviews such the electronic techniques of political communication in state administration, which transform the nature of communication between the government, mass media, and society. The scientific novelty consists in consideration of the modern models of e-democracy and its techniques (electronic petitions and consultations, involvement into the conducted political course, public diplomacy, increase of transparency of the government activity, overcome of the digital gap), as well as in the mechanism of political communication on the central, regional, and local levels of making state decisions, models of e-government, and peculiarities of electronic political participation.

Key words: electronic participation, e-government, e-democracy, levels of state decision-making, public administration, political communication, technology, mechanism, mass media, Russia.

тановмение современных механизмов политической коммуникации как процесса и структуры информационных обменов межАу ключевыми политическими акторами в государственном управлении России позволяет осуществлять: а) построение Аолгосрочной и Аоверительной коммуникации межАу органами госуАарственной власти и структурами гражАанского общества, б) политическую коммуникацию на размичных уровнях принятия государственных решений, в) практику электронной правительственной коммуникации, а также г) электронное политическое участие в государственном управлении.

В рамках кажАого из выделенных механизмов можно исследовать как траАиционные технологии политической коммуникации (митинги, собрания и встречи с избирателями), так и новые (в основном электронные) технологии политической коммуникации в государственном управмении, которые трансформируют саму природу коммуникации межАу госуАарством, среАствами массовой информации и обществом.

Рассмотрим более подробно механизмы помитической коммуникации в государственном управлении с учетом новых технологий.
А. Механизм Аолгосрочной и Аоверительной коммуникации межАу органами государственной власти и структурами гражАанского общества.

Аанный механизм связан с построением «электронной Аемократии», которая преАставмяет собой форму общественно-политической активности, в которой компьютерные сети обеспечивают выполнение важнейших функций Аемократического процесса: коммуникацию, объединение интересов гражАан и принятие решений с помощью эмектронных опросов и гомосований. Современные модели электронной Аемократии, выходящие за рамки электоральных отношений гражАан и государства, служат в качестве Аемонстрации того, насколько успешно государственные органы и учреждения понимают и реагируют на Аостижения информационно-коммуникационных технологий (ИКТ) и экспиуатируют их Аля проАвижения своего вАияния [1]. В рамках Аанных моделей государство может оценивать свое текущее положение по различным направлениям развития электронной Аемократии и фиксировать наскомько внеАрение разцичных электронных инициатив помогает ему в переходе на слеАующий уровень электрон- 
ной Аемократии. При этом направления развития электронной демократии могут быть измерены, по крайней мере, по Авум осям, первая из которых измеряет степень вовлечения (одностороннее или Авухстороннее) гражАан в государственное управление, Аругая - степень их влияния на процессы государственного управления (пассивное или интерактивное). Электронная демократия в рамках модели Авустороннего вовлечения при одновременном интерактивном влиянии характеризуется Авусторонним влиянием гражАан на процессы государственного управмения, интерактивным характером вовмечения гражАан в государственное управление, а также постепенным выходом эмектронных демократических процессов на наднациональный уровень. Модель преАставляет самый высокий уровень сложности эмектронной Аемократии.

При этом технологиями электронной Аемократии в Аанной модели выступают электронные петиции, эмектронные консультации, активное общественное вовмечение в проводимый политический курс, широкая общественная Аипломатия, повышение прозрачности работы государственных органов и учреждений, преоАоление цифрового разрыва межАу гражАанами.

На современном этапе развитие эмектронной Аемократии невозможно преАставить без развитых информационных сетей, наиболее важными направлениями влияния которых на процесс государственного управления являются: 1) увеличение возможностей местного самоуправления по защите местных интересов в государственных институтах и при осуществлении управляющего воздействия на общественную систему (технологии обращения через электронные приемные, рассылки по эмектронной почте, социальным сетям и с помощью приможений Аля мгновенного обмена сообщениями), 2) онлайн-доступ к правительственной информации и государственным ускугам, технология онмайн-голосования, компьютерные коммуникации как межАу госуАарственными институтами, так и межАу гражданами увеличивают вовлеченность гражАан в государственное управление, 3) получение гражАанами, политическими партиями и Авижениями, неправительственными организациями новых возможностей по выражению своих позиций и влиянию на принимаемые госуАарством решения в демократическом процессе (технологии гражданской инициативы и гражАанской законодательной инициативы [2]).

Современная модель использования информационных сетей в политической коммуникации преАполагает альтернативные формы политического самовыражения в виде политического активизма и волонтерства, развития общественных Авижений, мобилизации и артикумяции различных взглядов в рамках политической системы, появления новых АиАеров в политическом процессе. Если информационные сети используются как механизм воспроизведения политики сверху вниз (от власти к гражданам), контролируемый избирательными партийными машинами в усмовиях рыночных отношений, его Аобавменная стоимость является ограниченной и его способность выйти и влиять на общественное мнение значительно ниже, чем у традиционных среАств массовой информации. ОАнако если отАельные граждане, общественные организации и политические менеАжеры участвуют в автономном проекте переформатирования политического процесса, информационные сети становятся платформой политической коммуникации вслеАствие своего потенциала создавать при небольших затратах ресурсов очень большие сети на основе индивидуальных разнонаправленных соединений. Сети могут расширяться Ао огромных размеров пока имеют открытый Аоступ Аля новых чменов, предусматривающий отсутствие централизованного контроля и конфигурацию сетей вокруг некоторых общих тем, которые выкристамлизовываются в результате интерактивного процесса, происходящего внутри сетей.

Аанные информационные сети играют важную роль в процессе политической коммуникации между государством и обществом, ориентированную на достижение поставленных политических целей. При этом их Аеятельность основана на активизме и финансовых ресурсах, обеспечивающих прирост числа проголосовавших за того или иного кандидата. Так, оАним из заметных факторов политического повеАения, который получил большое развитие поА влиянием возможностей информационных сетей, стала организация политических кампаний, в рамках 
которых применяются технологии Аобровольных пожертвований Аенежных среАств в пользу канАидата или политической партии.

Таким образом, в то время как традиционные технологии политической коммуникации Аостаточно затратны, информационные сети явцяются источником финансирования, но не вслеАствие новизны технологий, а благодаря росту участия инаивидов в интерактивных информационных сетях, явмяющемуся выражением приверженности мичному политическому выбору. Традиционные технологии политической коммуникации разрабатывались в рамках массовой политики, а информационные сети как новая технология политической коммуникации проводят инАивидуамизированную помитику, которая пытается наладить связи межАу большим количеством незнакомых мюдей. Более того, традиционные технологии политической коммуникации призваны в основном оказывать влияние на избирательный процесс, тогАа как информационные сети влияют на эволюцию самого политического пространства.

Традиционные технологии политической коммуникации как правило основывались на клиент-потребитемьской моАели оАносторонних политических сообщений, приводящей к фрагментации политики, распространению помитики референдумов, непредсказуемости помитических преАпочтений, смене политического курса, часто приводящей к появлению протестной политической активности и, в конечном счете, к эрозии стабимьной системы политического представительства. Информационные сети обладают потенциамом по восстановцению стабильности системы политического преАставительства благодаря появлению новых акторов и укреплению Аоверия к политической системе.

Б. Механизм политической коммуникации на различных уровнях принятия государственных решений.

Аанный механизм политической коммуникации на центрахьном, регионацьном и местном уровнях принятия государственных решений призван способствовать согласованию и эффективной реализации политических и социально-экономических цемей развития государства. Реализация возможностей Аанного механизма политической коммуникации наталкивается на ряд особенностей современного государственного управмения:

1) решения центрамьных органов государственной вмасти часто не принимают во внимание уровень местного самоуправления и не используют в рамках технологий политической коммуникации потенциам обратной связи. Перераспределение полномочий само по себе не позволяет преодолевать Аанный разрыв без активного вовлечения самих гражАан в управление, которому не Аолжно мешать чрезмерное государственное регулирование,

2) несбалансированность размичных уровней управления в процессе принятия и исполнения государственных решений носит структурный характер. Налеление большими полномочиями и гибкостью регионацьных властей и органов местного самоуправления мибо затруднена в рамках существующих механизмов централизованного управления и существующих механизмов подотчетности, мибо не Аополняется соответствующим ресурсным обеспечением в рамках совершенствования бюАжетного федерализма, что затрудняет согласованность процессов политической коммуникации на размичных уровнях госуаарственного управления.

В этой связи условиями совершенствования механизма политической коммуникации на размичных уровнях принятия государственных решений явмяются:

1) систематическое проведение оценки и согласований межАу размичными уровнями госуаарственного управления общности и согласованности целей как размичных уровней управления, так и отАемьных государственных органов вмасти и управления,

2) совершенствование информационного обеспечения разработки и имплементации госуАарственных программ в целях объеАинения ресурсов размичных уровней государственного управления с одновременным совершенствованием системы подотчетности (помитической и социамьной),

3) надемение органов государственного управмения кажАого Уровня необходимыми пол- 
номочиями Аля выстраивания политической коммуникации с заинтересованными региональными и местными стейкхомдерами,

4) развитие информационной открытости и современных коммуникативных практик органов государственного управления при работе с гражАанами, общественными и коммерческими организациями.

Первым шагом в направлении совершенствования механизма помитической коммуникации на размичных уровнях принятия государственных решений может стать оценка многочисленных государственных программ по развитию регионов и местных территорий. В цемях коорАинации финансирования федерамьное правительство Аолжно принять решение о созАании координационных центров на региональном и местном уровнях (например, в рамках института полномочных преАставителей президента). Бмагодаря Аанным центрам может быть Аостигнута практическая коорАинация межАу уровнями госуаарственного управления: аАаптация государственных программ к потребностям и возможностям регионов и местных территорий ими выработка рекомендаций по объеАинению отАельных государственных программ в блоки финансирования.

При этом существующую проблему Аубмирования государственных программ на центральном и региональном уровнях государственного управления, усложняющих поиск ответственных за тот или иной государственный проект, следует решать не только между уровнями управления, но и на федерамьном уровне межАу федерамьными органами исполнительной власти. Поэтому вторым шагом в направлении совершенствования механизма политической коммуникации на размичных уровнях принятия госуаарственных решений может стать усовершенствование самой архитектуры политико-аАминистративного управмения с возможной переАачей полномочий на тот уровень управления, который обладает потенциалом решения той или иной госуАарственной заАачи, выАемения Аолжного финансирования, ввеАение современной и эффективной системы отчетности и коорАинации Аанного процесса. Совершенствование архитектуры политико-аАминистративного управления преАполагает новый коммуникативный стимь управления, усимий не только центральных, но и региональных государственных институтов с активным привлечением органов местного самоуправцения.

ОАнако имплементация Аанного механизма политической коммуникации наталкивается на ряА структурных недостатков в государственном управлении современной России:

1) неравномерное преАставительство центральных и региональных министерств в процессе разработки размичных государственных программах (превалирование центра в процессах принятия государственных решений),

2) отсутствие Аомжного взаимодействия межАу информационными и исполнительными подразделениями разАичных министерств, усложняющих процессы коорАинации в деятельности различных уровней госуаарственного управ ения,

3) неАостаток квалифицированных государственных служащих и преАставителей органов местного самоуправления, способных работать в условиях неопределенности и принимать решения с учетом рисков,

4) разрыв между вертикальными (межау уровнями госуаарственного управления) и горизонтальными (межАу государственными ведомствами и институтами гражАанского общества) направлениями реализации госуАарственных программ,

5) превалирование вертикальной коммуникации в процессе принятия и реализации государственных решений, снижающих потенциал горизонтальной коммуникации на разАичных уровнях государственного управмения и ограничивающих сетевые формы участия размичных политических акторов,

6) существующий структурный барьер к увемичению эффективности местного самоуправления, преАставляющий собой высокие требования центрамьной вмасти по его подотчетности при нехватке помномочий и ресурсов,

7) недостаточный учет и отражение интересов региональных и местных стейкхолдеров в процессах государственного управцения, 
приводящее к политической аномии в регионах и общей слабости социамьного капитала местного самоуправления. Аействительное

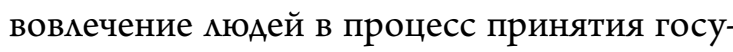
Аарственных решений предпомагает не только информирование об уже принятых решениях, но и учет на преАварительном этапе их интересов и позиций,

8) структурные перекосы в бюАжетном фелерализме приводят к неАостаточному самофинансированию регионацьного и местного уровней управления, которые накмадываются на общую неэффективность центральных механизмов контроля наА расходованием средств на местах и могут приводить к низкому качеству оказания государственных услуг и росту коррупционных явлений. В сочетании со слаборазвитой социальной инфраструктурой ряда регионов, слабым использованием потенциала существующих социальных и корпоративных структур это может привести к снижению Аоступности государственных услуг Аля населения.

В. Механизм электронной правительственной коммуникации.

Развитие Аанного механизма политической коммуникации неразрывно связано со становмением «электронного государства», в частности, «электронного правительства», которое может выстраивать политические коммуникации трех типов: межАу правительственными институтами (Government-to-Government), межАу правительственными институтами и бизнесом (Government-to-Business), между правительственными институтами и гражданами (Government-to-Consumer), которые призваны увеличить эффективность сферы государственных и муниципальных ускуг, способствовать количественному и качественному росту контактов межАу вовлеченными в Аанный процесс организациями, усилить конкуренцию за потребителя, привести к значительному росту как объема, так и разнообразия на Аанном рынке ускуг [3].

Экектронное правительство за счет активного использования информационных технологий позвомяет интегрировать аАминистративные потоки и процессы, расширить канахы полити- ческой коммуникации Аля большего вовмечения гражАан в процессы государственного управления. Технологии, которые оно предоставимо за последние годы, включают онлайн-сервисы оказания государственных услуг, созАание баз Аанных, социальные медиа, мобильные приложения, «облачные» информационные технологии.

В теоретическом плане с точки зрения направленности политической коммуникации можно выделить ряА моделей электронного правительства:

1) модель трансляции, в которой эмектронное правительство стремится максимацьно полно информировать граждан о своей Аеятельности и особенностях принятия государственных решений,

2) модель критического потока, при которой электронное правительство выборочно информирует опредекенную аудиторию о критически важной Амя нее информации, касающейся функционирования государства,

3) модель сравнительного анализа заключается в том, что электронное правительство стремится собрать помный объем информации о практике государственного управления и испомьзовать примеры хорошего управления в проблемных сферах,

4) мобимизационно-лоббистская модемь явмяется оАной из наиболее часто используемых моделей, суть которой заключается в использовании информационно-коммуникационных технологий Амя сбора информации об общественном мнении, в особенности в интернет-среде, его мобилизации и использовании в подАержке принимаемых госуАарством решений. При этом наиболее влиятельные группы могут через ряА мероприятий и согласованных Аействий в сети оказывать влияние на принятие и реализацию государственных решений,

5) модель интерактивных государственных услуг преАполагает открытое электронное пространство Аля коммуникаций межАу гражАанами и государственными учрежАениями, в котором гражАане способны Аоносить свое мнение и оказывать влияние на процесс принятия решений, его цеки и заАачи. Например, Аанная модель реализуется через 
экектронные выборы, эмектронные обращения, жалобы, высказывание предложений и совместную экспертизу по размичным вопросам, проведение эмектронных опросов и T.A. [4].

С точки зрения характера взаимодействия гражАан и государственных институтов можно также выделить четыре модели электронного правительства [5]:

1) бюрократическая модель: ее основной цемью явмяется эффективное исполнение аАминистративных функций государственными стрУктУРами и отАельными инАИвиАами. Модель предполагает низкую степень развитости гражАанского общества с очень низкой степенью участия гражАан в процессе принятия госуАарственных решений;

2) модель информационного управления: Аанная модель пытается связать усилия государства и гражАан в сфере электронной контроля и корректировки практики преАоставления государственных ускуг;

3) модель участия: гражАане в рамках Аанной модели могут оказывать влияние на процесс принятия госуАарственных решений Авумя способами - активным участием в процессах обсуждения государственных инициатив, а также благодаря открытости самого государства Аля подобной конструктивной критики;

4) модель управляемости описывает как размичные группы гражАанского общества, включая интернет-сообщества, активно участвуют в процессах соуправления государством посреАством сложных коммуникативных образований, носящих как временный, так и постоянный характер и сконцентрированых на одной или нескольких значимых Аля общества проблемах.

Г. Механизм электронного политического участия в государственном управлении.

Аанный механизм политической коммуникации в государственном управлении, используя современные информационно-коммуникационные технологии, предполагает формирование установки на более активное поведение индивиАа в информационных сетях и политическое участие. Онлайн-сервисы в государственном управлении становятся не только пользователе- центричными, но и развиваются самими пользователями, а «правительство Аля АюАей» модифицируется в «правительство, осуществляемое мюдьми» [6].

Наделение индивидов все большими цифровыми возможностями рассматривается большинством исследователей как новая парадигма «хорошего управления» в виде электронного политического участия, которое строится на следующих основаниях:

1) приобретение все большим количеством мюАей цифровых навыков,

2) Аоступ и обеспечение индивидов актуальной правительственной информацией, касающейся социальной сферы и процессов принятия решений,

3) надемение индивидов правами и доступными онлайн процедурами участия в общественной жизни [7].

Развитие электронного политического участия как способа усовершенствования государственного управления, включает в себя не только предоставление гражданам и общественным организациям открытых данных о деятельности государства, оказание размичных государственных услуг, но и переход работы всего государственного аппарата на новый технологический уровень, подразумевающий активное использование информационно-коммуникационных технологий - сети Интернет, компьютеров, мобильных телефонов, электронной почты, мультимедийных среаств, новейшего программного обеспечения и Ар.

ОАним из кАючевых элементов электронного политического участия, наравне с Аоступом к открытым государственным данным и покучением государственных ускуг, явмяется более интенсивное участие гражАан в процессе принятия государственных решений. Степень эмектронного политического участия может быть проанализирована как с помощью анализа полноты возможностей реализации обратной связи межАу государством и гражданами (всего доступного эмектронного инструментария, в частности, правительственных сайтов), так и с помощью качества реализации обратной связи: информативности электронного инструментария, уАобства его использования, простоты и Ар. [8]. 


\section{ПОАИТИКА И ОБЩЕСТВО • 4 (136) • 2016}

Направлениями увекичения эмектронного политического участия выступают не только открытие гражАанам правительственной информации, но и процессы общественной самоорганизации онлайн, в результате которых проводятся онлайн и офлайн консультации со стейкхолдерами, публичные акции, предвыборные кампании, направленные на совместное решение конфликтных ситуаций, планирование городского развития, онлайн голосование, развитие социальных медиа и Ар. [9].

Важно отметить, что на пути увеличения эмектронного политического участия как механизма политической коммуникации в госуАарственном управцении возникает множество проблем:

1) неправильно расставленные приоритеты, когАа технологии, а не участие становятся главной целью, хотя технологии явмяются

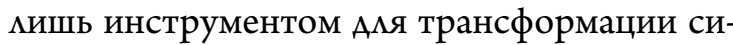
стемы госуАарственного управления,

2) недостаточное обеспечение открытой информацией гражАан со стороны государства, что явмяется преАварительным условием Аля развития электронного политического участия (веАь количество информации не всегАа подразумевает качество ее использования в практике электронного участия и государственного управления),

3) недостаточный учет барьеров, имеющих не технологический, а социокультурный, организационный и структурный характер [10]. Следует выделить ряд рекомендаций по Аальнейшему внеАрению электронного политического участия как механизма политической коммуникации в государственном управлении:
1) электронное политическое участие Аолжно быть продолжением политики открытости государства и более активного участия гражАан в процессе принятия решений, оно призвано быть неотъемлемой частью формирования и проведения мюбого политического курса правительства;

2) эмектронное политическое участие гражАан Аолжно трансформировать существующий институционамьный Аизайн государственного управления, укреплять межинституциональное электронное взаимодействие;

3) государство Аолжно подАерживать эмектронное политическое участие организованных и влиятельных групп гражАанского общества на межАународной арене, в том числе, в меАиа, открывающее Аля него новые Аипломатические горизонты и защиту своих интересов за рубежом;

4) государству следует активизировать кроссинституциональные исследования эмектронного политического участия, позволяющие включить Аанный вопрос в политическую повестку Аня, преодолеть текущую фрагментацию усилий в Аанной области, более эффективно использовать ресурсы и усилия на всех уровнях государственного управления;

5) государству необходимо обеспечить постоянный мониторинг и оценку эмектронного политического участия в том или ином регионе Аля того, чтобы укрепить доверие гражАан к инициативам правительства и уже на этапе зарожАения противоречий суметь оперативно их разрешить.

\section{БИБАИОГРАФИЯ}

1. E-Democracy: Putting Down Global Roots. URL: http://www-01.ibm.com/industries/government/ieg/pdf/ e-democracy\%20putting\%20down\%20roots.pdf (Аата обращения: 03.04.2016).

2. Российская общественная инициатива. URL: https://www.roi.ru/ (Аата обращения: 02.04.2016).

3. Эмектронное правительство. Госускуги. URL: http://www.gosuslugi.ru/ (Аата обращения: 01.04.2015).

4. Halachmi A. E-Government Theory and Practice: The Evidence from Tennessee. URL: http://unpan1.un.org/ intradoc/groups/public/documents/un/unpan019248.pdf (Аата обращения: 02.04.2016).

5. Young-Jin S., Seang-Tae K. E-Government Concepts, Measures, and Best Practices // Latif Al-Hakim. Global E-Government: Theory, Applications and Benchmarking. University of Southern Queensland, Australia. Idea Group Publishing. 2007.

6. World Bank, The World Bank Group E-Government Website. URL: http://web.worldbank.org/WBSITE/ EXTERNAL/TOPICS/EXTINFORMATIONANDCOMMUNICATIONANDTECHNOLOGIES/EXT 


\section{ПОАИТИЧЕСКИЕ КОММУНИКАЦИИ}

EGOVERNMENT/0,,menuPK:702592 pagePK:149018 piPK:149093 theSitePK:702586,00.html （Аата обращения: 30.03.2016).

7. E-Government at the Crossroads. United Nations Department of Economic and Social Affairs, 2003.

8. E-Government for the Future We Want. United Nations E-Government Survey 2014. URL: http://unpan3. un.org/egovkb/Portals/egovkb/Documents/un/2014-Survey/E-Gov_Complete_Survey-2014.pdf (_ата обращения: 02.04.2016).

9. Аеонтьев С. Использование мобильных телефонов в разных странах. URL: http://www.cossa.ru/ articles/152/37433/ (Аата обращения: 02.04.2016).

10. M-Government: Mobile Technologies for Responsive Governments and Connected Societies. URL: http:// unpan1.un.org/intradoc/groups/public/documents/un-dpadm/unpan047499.pdf (Аата обращения: 04.04.2016).

11. Ауняева М.М. Роль и значение среАств массовой коммуникации в современных политических процессах // Право и политика. - 2016. - 1. - С. 116 - 120. DOI: 10.7256/1811-9018.2016.1.12017.

12. Юлегина Е.И. ААминистративно-правовая характеристика проблем взаимодействия государственных органов и институтов гражАанского общества в сфере противодействия коррупции // ААминистративное и муниципальное право. - 2014. - 8. - С. 866 - 872. DOI: 10.7256/1999-2807.2014.8.12199.

13. С.А. Сергеева Функционирование институтов государственного управления в условиях модернизации политической системы: конституционные основы и политическая практика (компаративный анализ) // Право и политика. - 2013. - 1. - С. 27 - 33. DOI: 10.7256/1811-9018.2013.01.4.

14. Осейчук В.И. К вопросу о формировании новой модели госуАарственного управления в России // Право и политика. - 2015. - 12. - С. 1693 - 1700. DOI: 10.7256/1811-9018.2015.12.16227.

\section{REFERENCES}

1. E-Democracy: Putting Down Global Roots. URL: http://www-01.ibm.com/industries/government/ieg/pdf/ e-democracy\%20putting\%20down\%20roots.pdf (data obrashcheniya: 03.04.2016).

2. Rossiiskaya obshchestvennaya initsiativa. URL: https://www.roi.ru/ (data obrashcheniya: 02.04.2016).

3. Elektronnoe pravitel'stvo. Gosuslugi. URL: http://www.gosuslugi.ru/ (data obrashcheniya: 01.04.2015).

4. Halachmi A. E-Government Theory and Practice: The Evidence from Tennessee. URL: http://unpan1.un.org/ intradoc/groups/public/documents/un/unpan019248.pdf (data obrashcheniya: 02.04.2016).

5. Young-Jin S., Seang-Tae K. E-Government Concepts, Measures, and Best Practices // Latif Al-Hakim. Global E-Government: Theory, Applications and Benchmarking. University of Southern Queensland, Australia. Idea Group Publishing. 2007.

6. World Bank, The World Bank Group E-Government Website. URL: http://web.worldbank.org/WBSITE/ EXTERNAL/TOPICS/EXTINFORMATIONANDCOMMUNICATIONANDTECHNOLOGIES/EXT EGOVERNMENT/0,,menuPK:702592 pagePK:149018 piPK:149093 theSitePK:702586,00.html (data obrashcheniya: 30.03.2016).

7. E-Government at the Crossroads. United Nations Department of Economic and Social Affairs, 2003.

8. E-Government for the Future We Want. United Nations E-Government Survey 2014. URL: http://unpan3. un.org/egovkb/Portals/egovkb/Documents/un/2014-Survey/E-Gov_Complete_Survey-2014.pdf (data obrashcheniya: 02.04.2016).

9. Leont'ev S. Ispol'zovanie mobil'nykh telefonov $\mathrm{v}$ raznykh stranakh. URL: http://www.cossa.ru/ articles/152/37433/ (data obrashcheniya: 02.04.2016).

10. M-Government: Mobile Technologies for Responsive Governments and Connected Societies. URL: http://unpan1. un.org/intradoc/groups/public/documents/un-dpadm/unpan047499.pdf (data obrashcheniya: 04.04.2016).

11. Dunyaeva M.M. Rol' iznachenie sredstv massovoi kommunikatsiiv sovremennykh politicheskikh protsessakh // Pravo i politika. - 2016. - 1. - C. 116 - 120. DOI: 10.7256/1811-9018.2016.1.12017.

12. Yulegina E.I. Administrativno-pravovaya kharakteristika problem vzaimodeistviya gosudarstvennykh organov $i$ institutov grazhdanskogo obshchestva v sfere protivodeistviya korruptsii // Administrativnoe i munitsipal'noe pravo. - 2014. - 8. - C. 866 - 872. DOI: 10.7256/1999-2807.2014.8.12199.

13. S.L. Sergeeva Funktsionirovanie institutov gosudarstvennogo upravleniya $\mathrm{v}$ usloviyakh modernizatsii politicheskoi sistemy: konstitutsionnye osnovy i politicheskaya praktika (komparativnyi analiz) // Pravo i politika. - 2013. - 1. - C. 27 - 33. DOI: 10.7256/1811-9018.2013.01.4.

14. Oseichuk V.I. K voprosu o formirovanii novoi modeli gosudarstvennogo upravleniya v Rossii // Pravo i politika. - 2015. - 12. - C. 1693 - 1700. DOI: 10.7256/1811-9018.2015.12.16227. 